\title{
Stability of the Cournot-Nash Equilibrium in Standard Oligopoly
}

\author{
A. JAKIMOWICZ \\ Department of Quantitative Methods, Faculty of Economic Sciences, University of Warmia and Mazury, M. \\ Oczapowskiego 4, PL-10-719 Olsztyn, Poland
}

The 19c. physics is a cognitive archetype of contemporary economics, where static, linear, closed systems that head for thermodynamic equilibrium were of great importance. In this standard of scientific knowledge were included selfish aspirations of agents, which served to prove stability of market equilibrium. The strive of entrepreneurs after profit maximization brings economic systems to a stable Cournot-Nash state of equilibrium, which is determined by the point of crossing of reaction curves. This type of reasoning still sets standards for education of microeconomics. Meanwhile, numerical explorations of simple, standard, nonlinear models of oligopoly prove that Cournot-Nash points are stable only over shortest periods. These are periods in which variables are changing (production values), and parameters (marginal costs) remain constant. According to a convention adopted in economics, in short periods various kinds of costs can change, including marginal costs. The only unchanging category in these periods are fixed costs. The postulate of profit maximization induces entrepreneurs to lower marginal costs. It provokes drifting of markets along short-term equilibrium states towards states of higher complexity. States far from equilibrium are natural market states. It contradicts the basics of traditional microeconomics. Selfish aspirations of agents do not guarantee stability of market equilibrium.

PACS: 89.65.Gh, 02.50.Le, 05.45.Ac

\section{Introduction}

According to conventional economics, the CournotNash equilibrium constitutes a natural state of oligopoly $[1,2]$. The achieved effect of convergence to equilibrium results from generally accepted practices in microeconomics which consist in reducing economic relationships to straight lines. Numerical explorations of selected nonlinear duopoly and triopoly models prove that there are two active kinds of economic forces in these market structures. The first of them, which has been described at length in microeconomics textbooks, leads market structures to the point of equilibrium determined by the intersection of reaction functions. The second, which is often omitted by economists, makes the path of equilibrium lead to the edge of chaos [3]. In a short period, systems head for the Cournot-Nash equilibrium, however, in the long run, there is a drift along the points of equilibrium toward the edge of chaos. The source for each of these forces lies in the desire of producers to maximize profit. This objective is achieved through a reduction in marginal cost.

The results presented here are a continuation of my earlier research on the dynamic nonlinear oligopoly theory [4]. They lead to a conclusion that model market structures are complex adaptive systems. The increase in complexity resulting from the approach of these system to the edge of chaos means that the degree of their compatibility to the surroundings simultaneously grows too. Systems with too low or too high degree of complexity have small adaptive capacity. It is probable that the state of the edge of chaos is characterized by optimal degree of complexity, hence the computational power of markets is close to maximum. It allows them not only to survive, but also to grow and develop. It seems that in the cases explored here, apart from the edge of chaos, we are also dealing with anti-chaos that comes from emergence. It would mean that in the long period, market structures automatically adjust to the edge of chaos, thus they display a certain kind of quasi-intelligence. There is a need for further research in this field.

\section{The Cournot-Puu duopoly model}

The easiest form of oligopoly is duopoly. An important place in the theory of economics is held by the CournotPuu duopoly model [5-8]. In this model a market of a given good is balanced, demand equals supply, supply is a sum of production provided by two companies, and marginal costs of both manufacturers are constant (in the short run). The function of demand is isoelastic, the price is the opposite of total demand:

$$
p=\frac{1}{x+y},
$$

where $p$ stands for price, whereas $x$ and $y$ respectively stand for the volumes of production of the first and the second company. Maximization of profit is the basis for 
economic activity. The first entrepreneur seeks the maximum of function $\mathrm{U}$ against the variable $x$, whereas the second entrepreneur seeks the maximum of function $\mathrm{V}$ against the variable $y$ :

$$
\begin{aligned}
& U(x, y)=\frac{x}{x+y}-a x, \\
& V(x, y)=\frac{y}{x+y}-b y .
\end{aligned}
$$

Marginal costs of duopolists are marked with $a$ and $b$ symbols. The functions of reaction are determined by comparing partial derivatives of both functions of profit to zero:

$$
\begin{aligned}
& \frac{\partial U}{\partial x}=\frac{y}{(x+y)^{2}}-a=0 \quad \Rightarrow \quad x=\sqrt{\frac{y}{a}}-y, \\
& \frac{\partial V}{\partial y}=\frac{x}{(x+y)^{2}}-b=0 \quad \Rightarrow \quad y=\sqrt{\frac{x}{b}}-x .
\end{aligned}
$$

Both reaction curves cross at point $\mathrm{E}$, which is called a Cournot-Nash point of equilibrium (Fig. 1). Its coordinates can be determined by solving the following set of equations (4)-(5):

$$
\begin{aligned}
& x_{e}=\frac{b}{(a+b)^{2}}, \\
& y_{e}=\frac{a}{(a+b)^{2}} .
\end{aligned}
$$

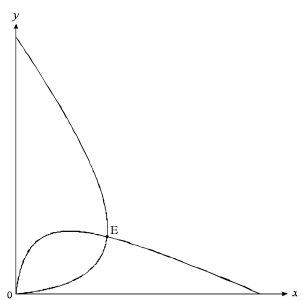

Fig. 1. Reaction curves and the Cournot-Nash equilibrium point.

The adaptation process analysis is possible only when variables $x$ and $y$ are dated. Equations (4)-(5) take up the following form:

$$
\begin{aligned}
& x_{t+1}=\sqrt{\frac{y_{t}}{a}}-y_{t}, \\
& y_{t+1}=\sqrt{\frac{x_{t}}{b}}-x_{t} .
\end{aligned}
$$

We thus get a basic version of the duopoly model. Entrepreneurs move on to new positions of equilibrium based on decisions on the production volume made by their competitor in the previous period.

Numerical explorations of the system (8)-(9) can be started with drawing a period plot (Fig. 2). This is a matrix that consists of $1440 \times 1440=2073600$ numbers. The navy-blue color stands for locations of equilibrium, and the red bands are the cycle of period 4. Divergent trajectories are marked white. Marginal cost is a category associated with future. Each entrepreneur is go-

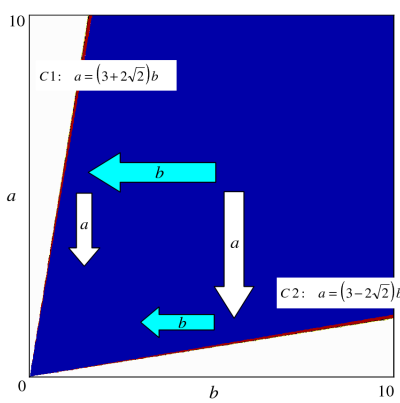

Fig. 2. Period plot for duopoly model and two linear edges of chaos.

ing to strive for profit maximization (reduction in the marginal cost). If the first duopolist minimizes marginal cost, he will reach the bottom edge of chaos (C2). If the second duopolist maximizes profit, he will reach the top edge of chaos (C1). Chaotic parameters account for mere $0.15 \%$ of the picture, but from an economic point of view it is the most important kind of behavior of this market structure.

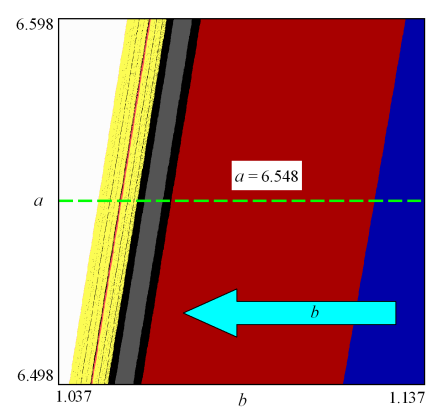

Fig. 3. Enlargement of the period plot and the edge of chaos $\mathrm{C} 1$.

Fig. 3 shows the enlargement of period plot. This picture presents the edge of chaos (C1). The black area represents cycles of periods exceeding 4 , and the yellow band stands for chaotic dynamics. Chaotic band is split by periodic behavior of period 12 (the bright-red line). If the second entrepreneur minimizes his marginal cost, the system loses its stability (the navy-blue area) and there appears a cycle of period 4 (the red area). Further reduction in marginal cost results in a chaos. The scenario of chaos appearance can be determined by drawing a bifurcation graph. It consists in making a cut of the graph along the green dotted line.

Transition from the state of equilibrium to the edge of chaos is described by a cascade of period-doubling bifurcations (Fig. 4a). The first bifurcation is a transition from a stable constant point to cycle of period 4 . It is true that we see a cycle of period 2 on a graph, but it is good to remember that a system is built of two independent iteration processes. Fig $4 \mathrm{~b}$ shows the Lyapunov exponent bifurcation diagram for the model. Every edge 


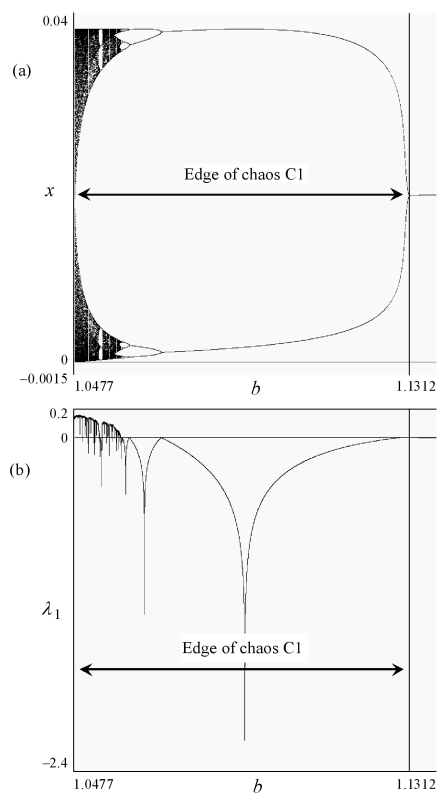

Fig. 4. Duopoly bifurcation scenario $(a=6.548$, $1.0477<b<1.1312$ ): (a) production of the first enterprise; (b) Lyapunov exponent.

of chaos, $\mathrm{C} 1$ and $\mathrm{C} 2$, stretches from the first bifurcation, where the fixed point loses its stability, up to such a value of marginal cost $b$, for which the trajectories become divergent. The growth in system complexity is caused by a drop in marginal cost of the second entrepreneur.

\section{The triopoly model}

The assumptions of triopoly are identical with the duopoly, the only difference being the third producer comes to play $[9,10]$. If we mark the production of the third entrepreneur with $z$, and their marginal cost with $c$, we will get the following oligopoly model:

$$
\begin{aligned}
& x_{t+1}=\sqrt{\frac{y_{t}+z_{t}}{a}}-y_{t}-z_{t}, \\
& y_{t+1}=\sqrt{\frac{x_{t}+z_{t}}{b}}-x_{t}-z_{t}, \\
& z_{t+1}=\sqrt{\frac{x_{t}+y_{t}}{c}}-x_{t}-y_{t},
\end{aligned}
$$

The period plot for this system (Fig. 5) shows a structure I named the chaotic heart of business. This object is symmetrical with lines $b=c$. The heart of business has a thin chaotic border. It is the edge of chaos. The participation of chaotic parameters accounts for mere $0.11 \%$, but from an economic point of view it is the most important kind of behavior. As it is the case with a duopoly model, a drop in marginal costs of the second and third company brings the system to the edge of chaos (chaotic border). It is assumed that the cost of the first producer is constant and equals 1 . The stability area is limited from all sides, which means that also an increase in marginal cost can lead the system to the edge of chaos. The white area stands for divergent trajectories.

The scenario of transition to the edge of chaos (kinds of bifurcations) can be determined by plotting bifurcation graphs. In order to do that we cut the period graph (Fig. $5)$ along line $b$. Fig. 6a shows the bifurcation diagram

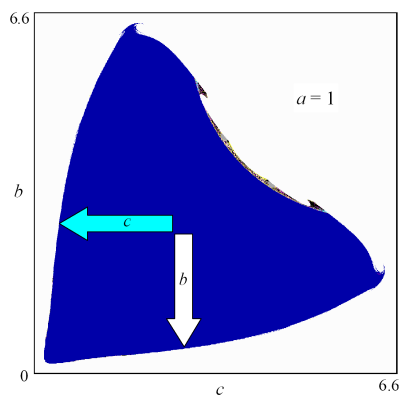

Fig. 5. Chaotic heart of business.

for the oligopoly model (10)-(12). Reaching the edge of

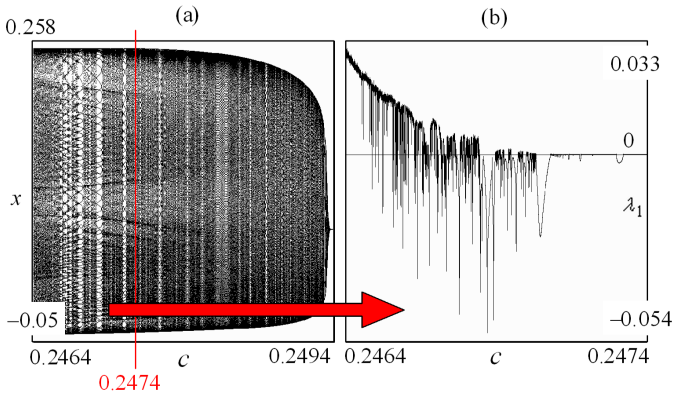

Fig. 6. Bifurcation phenomena in the triopoly model: (a) production of the first enterprise; (b) Lyapunov exponent.

chaos happens through a sequence of Hopf bifurcations. Initially a drop in marginal cost of the third entrepreneur results in cyclical fluctuations of production of the first entrepreneur. There appear periodic attractors with high period. Further drop in marginal cost results in reaching the edge of chaos. The bifurcation diagram of the variable $x$ has an unusual structure and it is very similar to some textile products. The bifurcation graph of Lyapunov exponent (Fig. 6b) has been limited to a range of 0.2474 to 0.2464 , since it is there where chaos occurs.

\section{Conclusions}

According to neoclassical economics the main purpose of corporate activities is to maximize profit. Such strives of entrepreneurs bring markets to the point of CournotNash equilibrium. This type of equilibrium is considered to be durable. Numerical explorations of archetypal duopoly and triopoly models prove that such states of equilibrium are stable only for a short period. In the long run the explored systems strive for the edge of 
chaos. Adding the third company results in a change in the scenario of chaos origin. In the case of duopoly it is a sequence of period-doubling bifurcation, whereas in the case of triopoly it is a sequence of Hopf bifurcations. Reaching equilibrium within a short period and the edge of chaos within a long period is caused by the same force - the strive of entrepreneurs to maximize profit. We need to make an appropriate revision of our textbooks on microeconomics.

\section{References}

[1] A. Cournot, Mathematical Principles of the Theory of Wealth, James \& Gordon, San Diego 1995.

[2] J. Nash, Annals of Mathematics 54, 286 (1951).
[3] C.G. Langton, Physica D 42, 12 (1990).

[4] A. Jakimowicz, Źródła niestabilności struktur rynkowych, seria: Współczesna Ekonomia, Wydawnictwo Naukowe PWN, Warszawa 2010.

[5] T. Puu, Chaos, Solitons, and Fractals 1, 573 (1991).

[6] T. Puu, Nonlinear Economic Dynamics, SpringerVerlag, Berlin 1997.

[7] T. Puu, Attractors, Bifurcations, and Chaos. Nonlinear Phenomena in Economics, Springer-Verlag, Berlin 2000.

[8] J. S. Cánovas, D. L. Medina, Discrete Dynamics in Nature and Society 2010 (2010).

[9] T. Puu, Chaos, Solitons, and Fractals 7, 2075 (1996).

[10] A. Agliari, L. Gardini, T. Puu, Chaos, Solitons and Fractals 11, 2531 (2000). 